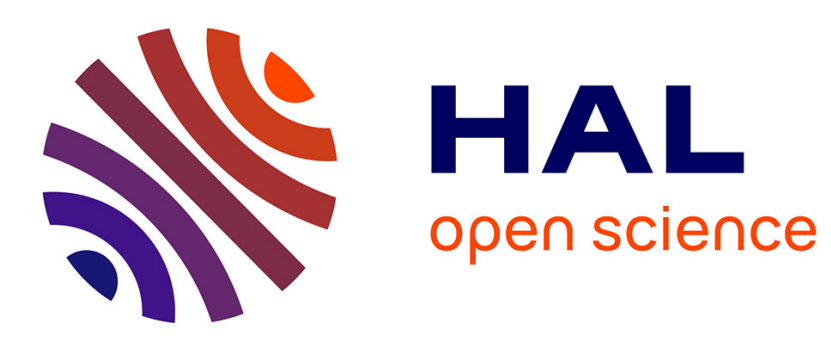

\title{
Outdoor recreation in a Regional Park: types of hikers, ski tourers and snowshoers in the Hautes-Bauges (Savoie, France)
}

\author{
Clémence Perrin-Malterre, Laine Chanteloup, Léna Gruas
}

\section{To cite this version:}

Clémence Perrin-Malterre, Laine Chanteloup, Léna Gruas. Outdoor recreation in a Regional Park: types of hikers, ski tourers and snowshoers in the Hautes-Bauges (Savoie, France). Annals of Leisure Research, 2021, 24 (5), pp.209-227. 10.1080/11745398.2019.1682016 . hal-02467743

\section{HAL Id: hal-02467743 \\ https://hal.science/hal-02467743}

Submitted on 5 Feb 2020

HAL is a multi-disciplinary open access archive for the deposit and dissemination of scientific research documents, whether they are published or not. The documents may come from teaching and research institutions in France or abroad, or from public or private research centers.
L'archive ouverte pluridisciplinaire HAL, est destinée au dépôt et à la diffusion de documents scientifiques de niveau recherche, publiés ou non, émanant des établissements d'enseignement et de recherche français ou étrangers, des laboratoires publics ou privés. 


\title{
Annals of Leisure Research
}

\section{Outdoor recreation in a Regional Park: types of hikers, ski tourers and snowshoers in the Hautes-Bauges (Savoie, France)}

\author{
Clémence Perrin-Malterre*, Laine Chanteloup** and Léna Gruas* \\ *Department of sport sciences, Univ. Grenoble Alpes, Univ. Savoie Mont-Blanc (USMB), \\ CNRS, Environment Dynamics and Territories of Mountains (EDYTEM), Chambéry, France; \\ **Department of geography, Géolab, University of Limoges, Limoges, France
}

\begin{abstract}
The objective of this paper is to analyse the modalities of practice for winter and summer activities (hiking, ski touring and snowshoeing) in the Massif of Bauges. Modalities of practice are defined from several variables such as level, frequency, and motivation. The methodology combined a quantitative method based on a survey with a qualitative method based on semistructured interviews. From a general standpoint, the profiles of recreational users in the Massif of Bauges are compatible with the previous observations made of those visiting natural areas, and especially of those participating in adventure sports. They are mainly men over 40 years old, who are university graduates and belong to privileged social categories. Results highlight individuals' different usages of the same activity. Also, it is possible to identify an age and gender effect in the structuring of the modalities of practice.
\end{abstract}

\section{Introduction}

Since the late twentieth century, the practice of sports has continued to expand worldwide, taking increasingly diversified forms (Borgers et al. 2015). There has indeed been a transformation of sports into leisure (Bessy 2008; Augustin 2011). Conviviality, pleasure and hedonism are the values that practitioners share, ahead of the quest for performance (Wheaton 2014). Many sources attest to the multiplication of informal sports practiced outside of institutions, even surpassing the growth of many traditional sports in Western countries (Wheaton 2010; Green, Thurston, and Vaage 2015). The most distinctive trend emerging is the enthusiasm for sports activities practiced in the great outdoors. In France, a survey conducted in 2010 on physical and sports activities revealed that outdoor sports were at the top of the list of favourite activities (Thiéry 2013). When all types of practices are combined, institutional or not, this represents nearly 25 million people who declared an outdoor sports activity, with hiking and cycling the most often mentioned. The contact with nature appears to be one of the practitioners' main motivations. This 'ecologization of practices' (Pociello 1995, 203) is linked to an enthusiasm for activities that go beyond simple institutional frameworks and are practiced in self-organized forms in multiple locations, especially in natural environments. These practitioners are strongly attracted to nature. Arnould and Price (1993) demonstrated that one of the satisfying factors in a recreational experience is the communion and harmony with nature. Moreover, this trend is expected to accentuate in the near future as the public's environmental awareness grows (Breivik 2010; Humberstone, Prince, and Henderson 2015). This social diffusion of outdoor recreation should not hide the fact that the demand for nature based activities is characterized by a wide sociological heterogeneity of the meanings granted to the different practices (Audinet, Guibert, and Sébileau 2017). Indeed, there is not one but several ways to get involved in an activity. 
Different typologies that allow better knowledge of the practitioners of outdoor sports can be elaborated. The national survey on recreation and the environment in the USA since the 1960s allows, for example, the collection of sociodemographic statistical data on the involvement of Americans in outdoor recreation and their interest for wildlife, nature, and the environmental values. Depending on the objectives (marketing surveys, better management of a protected area, conflict management), various typologies are made to identify sub-groups based on classification indicators such as sociodemographic dimensions, psychographic items and motivations (Torbidoni 2011; Salome and Van Bottenburg 2012; Lee et al. 2016). The aim of these studies is to describe reality rather than to

causally explain a phenomenon. Similarly, our study is exploratory rather than confirmatory. The objective of this paper is to analyse the modalities of practice (Lahire 2004) for winter hiking activities (ski touring and snowshoeing) and summer hiking activities in a low mountain massif. Modalities of practice are defined from several variables such as level in the activity, frequency, and motivation. The massif of Bauges is a rural mountain space, of which one part is protected, classified as a National Wild Fauna and Game Reserve (RNCFS). From a tourism standpoint, the massif is especially appreciated by hikers in summer, and by ski tourers and snowshoers in winter. Since we are dealing with non-organised activities, a large majority of the participants are not affiliated with associations or mountain federations, which makes it difficult to know the people involved in these sports.

Yet, knowing the types of practitioners visiting the massif is fundamental for the Game Reserve managers. Indeed, the development of outdoor sports raises numerous issues connected with tourism development (access control, accessibility, cleanliness) and management of conflicts between different sports but also between outdoor sports and other Reserve users (farmers, hunters, etc.). A better knowledge of visitors and visitor numbers is also important to take into account when considering public safety issues (avalanche risks management and mountain rescue organization) and environmental issues (Pigram and Jenkins 2006; Ankre, Fredman, and Lindhgen 2016). The Hautes-Bauges territory and the Game Reserve have to consider the high stakes of wildlife disturbance and develop communication and education campaign to raise awareness among visitors (Immoos and Hunziker 2015). This is why one of the three comanagers ${ }^{1}$ of the Game Reserve, the Regional Park of Bauges Massif, preoccupied with the increase in outdoor sports practices and their impacts on wildlife, expressed an interest in acquiring more in-depth knowledge of these sports practices by focusing in particular on who are the practitioners and what are their representations in order to better target awareness campaigns and adapt management measures to the types of visitors and of practices (Manning 2010; Gundersen et al. 2015).

\section{Modalities of outdoor and mountain sports practices}

Outdoor sports, have been growing since the late twentieth century. Studies conducted on the practitioners have shown that at the outset most of them were young, white, Western men from the middle class (Robinson 2004; Wheaton 2004). However, the growth of these sports has broadened practitioner recruitment, resulting in a wide variety of experiences and levels of practice, and now also including women, young people and seniors (Breivik 2010; Wheaton 2010). In the mountain, Beedie and Hudson (2003a, 640) observe a democratization process of mountaineering, an activity that has become 'more accessible, both socially and physically, to more people than ever before'. Therefore, outdoor sports can no longer be reduced to a small group with homogenous traits (Salome and Van Bottenburg 2012) and it is necessary to establish a typology of practitioners.

\footnotetext{
${ }^{1}$ The RNCFS is co-managed by the Office National de la Chasse et de la Faune Sauvage, the Parc Naturel Régional du Massif des Bauges and the Office National de la Forêt
} 
Sports sociology research conducted in the 1980s made it possible to build, in a structuralist perspective, a sports space enabling the identification of homological links between activities and a practitioner's social origin (Pociello 1981). The choices of practices could then be explained by the logic of distinction (Bourdieu 1979). Today's massive consumption of sports practices refutes the idea that the choice of a sport is almost exclusively made in the sense of social differentiation. In France, only nine out of 270 activities are significantly done more by higher social categories, and only three are done more by lower social categories (Ohl and Taks 2008). However, there are still differences linked to social categories in mountain sports. Thus, skiing and hiking in the mountains remain distinctive activities and are significantly more attractive for the higher social categories (Lefèvre and Ohl 2012). Moreover, upper social groups in France remain distinguishable, in terms of both their 'high level of omnivority' and their choice of modalities of practice (Lefèvre and Ohl 2012). Therefore, it is important to analyse the socially differentiated ways of practicing the same sport: 'given that a sport always attracts socially diversified populations, one can attempt to understand how the different categories of practitioners take ownership of the activity in question' (Lahire 2004, 29).

If we place ourselves in this structuralist perspective, we can imagine that the way to practice a sports activity is guided by socially acquired dispositions. Dispositionalism is defined as a 'sociology of socialisation which studies the dispositionalist traces left by past social experiences as well as the way those dispositions are triggered (or are put on standby) in various contexts' (Lahire 2007, 315). It is a sociology that takes into account the differentiated use of one activity (Lahire 2013). The analysis highlights the variables that influence the investment in a practice. Indeed, surveys carried out at a large scale show that behaviours never distribute randomly, depending on the social conditions, age range, sex, social position or origin, or level of education of participants. Thus, dispositionalist sociology is consistent with those studies which use statistical approaches to classify participants depending on their socio-demographic variables because these studies enable us to look for the most discriminant variable depending on the field of practice that is being studied. According to this individual level sociology, sociodemographic variables can explain the existence of different practices in an activity.

In the field of outdoor sports in mountain environments, studies have highlighted different ways to get involved in an activity. They have focused on canoeing-kayaking (Lapierre 1981), free flight (Jorand 2000), cross-country skiing (Roult et al. 2017), summer activities in the mountains (Corneloup 2003), high mountains (Lefèvre 2004), and canyoneering (Suchet and Jorand 2009; Hardiman and Burgin 2011). Studies by Corneloup (2003) and Roult et al. (2017), notably, made it possible to identify different forms of summer and winter practices in the mountains. These studies enabled the building of practitioners' typologies by including sociodemographic variables such as social background, age, gender, income, level of education. Some authors have shown the influence of these variables on motivations to practice an activity (Sport England 2015), particularly gender and age (O'Connell 2010). As far as gender is concerned, Ko, Park, and Claussen (2008) have shown that men are more motivated by the mastery of skills, competition and the affiliation with a peer group. Ewert et al. (2013) show that females have higher social motives than males. In relation to age, Kerr and Houge Mackenzie (2012) show that motives might change for individuals with time as participants gain experience or age. In this context, youngermountaineers are more motivated by challenge than older ones (Pomfret and Bramwell 2014).

Using the same perspective, we intend to conduct an analysis of the modalities of practices of winter hiking activities (ski touring and snowshoeing) and summer hiking activities in the Massif of Bauges. These activities have been studied in the Artic (Berbeka 2018) and South Korea (Kim and Song 2017), but not yet in France and especially in Les Bauges Game Reserve. Thus, this study will contribute to the resource management of the Massif of Bauges. 


\section{Methods}

Our survey of the practitioners was conducted in the Massif of Bauges from January to April in 2015 and 2016, and from June to August in 2016. The methods used combined a quantitative method based on a survey with a qualitative method based on semi-structured interviews.

\section{Study participants}

Five hundred and fifty-eight visitors were interviewed through a questionnaire during the winter season, and 505 during the summer season. The questionnaires were filled out face to face on the two parking lots at the start of the hiking trails, at a frequency of two days during the week and one day on the weekend. Very few individuals refused to respond to the questionnaire, and the reasons given for these refusals were mainly linked to limited time. As for the sampling, all of the practitioners present on the site were approached, without taking into account their sociodemographic characteristics or the activities practiced. The two samples can therefore be considered representative of the site users.

We conducted 35 interviews with winter practitioners and 8 interviews with summer ones. Interviewees were not chosen so as to be statistically representative of the questionnaire sample. Rather, they were selected in order to illustrate the categories of practitioners from the typology built thanks to the multivariate analysis of the quantitative survey. So, we interviewed individuals from the sample affiliated with each sub-group.

\section{Measures}

Since we intend to connect sociodemographic variables and modalities of practice our questionnaire comprised three sections:

- the characteristics of the sports activity involved in the outing conducted when the questionnaire was filled out (duration, destination, reasons for choosing the Massif of Bauges), the practice of the activity in general (years of experience, frequency, level, membership in a federation, reasons for practicing ${ }^{2}$, etc.), and also the other physical and sports activities engaged in during the year;

- the perception of the natural environment and wildlife, a section of the questionnaire that will not be examined in the context of this study;

- the respondents' socio-demographic characteristics: gender, age, socio-professional category, income bracket, marital situation, number of children, municipality of residence.

The interview guide comprised two sections:

- the practice of the sports activity,

- the practitioners' perception of the natural environment and their opinions concerning mountain management (from the development of infrastructures to the implementation of protective measures).

As this article aims to identify the types of practitioners depending on sociodemographic data and motivation, we mainly looked at data related to sport practice and what people seek in their practice.

\footnotetext{
${ }^{2}$ For example, two items for reasons of practice were: 'I practice this activity to stay fit'; 'I'm looking for risk taking'.
} 
To establish practitioner typologies, we applied a Multiple Correspondence Analysis (MCA) from the questionnaires, using the Trideux 5.1 software programme. As it was used by Suchet (2009) to categorize different canyoneering practitioners, this method allows us to identify statistical links between several modalities (Ganassali 2007) and to establish typologies of participants sharing similar characteristics. We chose this method because it allows us to describe a social reality and to spot associations between variables. Contrary to regression methods, it does not look for dependence and causality between the variables (Nétumières 1997). This method has an "exploratory value and consequent absence of a priori assumptions concerning the nature of the distribution of variables. Moreover, it possesses excellent descriptive powers, since it allows one to examine the simultaneous interaction of many variables by exploring their direct links" (Di Franco 2016, 1307). This technique aims at providing a summarized representation of a high number of variables through a reduced number of factors.

In order to have a better understanding of sport practices, we included in the analysis the following active variables: main motivation to practice the activity, level and frequency of practice, difficulty of the itineraries, and whether the individual competes in the activity. Then, we included as supplementary variables: occupation, monthly income, age and gender. All the variables are categorical, except for 'age' which is continuous, but was classified to become categorical. To improve the analysis, we have eliminated low-frequency categories and recoded the variables in order to rebalance the distribution of the cases within the categories of each variable $^{3}$. Six factors were generated and we retained the two factors with the highest proportion of variance.

"In order to the [sic] interpret of [sic] the graphs produced by this kind of analysis, the main criterion is looking at of [sic] the closeness between categories. If two categories present high coordinates and are close in space, this means that they tend to be directly associated" (Di Franco 2016, 1306).

Semi-directive interviews were entirely transcribed. A thematic analysis was performed, consisting of 'systematically proceeding with the identification, the grouping, and subsidiarily, the discursive examination of the themes addressed in a corpus' (Paille and Mucchielli 2003, 123). The thematic unit is 'a core meaning identifiable according to the issue and the hypotheses of the research' (Blanchet and Gotman 2005, 98). The themes were selected according to the theoretical framework and represented a stable analysis framework for all of the interviews. It was therefore a closed categorization procedure (Ghiglione and Matalon 1991), since all of the themes had been defined prior to the analysis. The analysis first focused on each individual interview to determine the modalities of practice of the interviewees. Then, a comparative data analysis allowed us to spot similarities between respondents and to draw out the mutual characteristics of the modalities.

\section{Results}

In the results section, the quantitative data presented in percentages comes from the questionnaires and the quotes come from the individual interviews.

\footnotetext{
${ }^{3}$ For example, we have eliminated low-frequency categories like 'farmer' andwe have recoded the variable 'level of practice' by combining 'beginners' and 'intermediate' (for the winter season).
} 


\section{The winter practitioners}

In the winter, most respondents were men $(75 \%)$ in the $31-45$-year-old age bracket. Their educational level was high, with $63.5 \%$ having a university degree (bachelor or higher), $44.2 \%$ had degree equivalent to or higher than a Master's. Managers and higher intellectual occupations were over-represented, accounting for 39\% of the sample, versus $14.3 \%$ of the overall French working population. As for their salaries, 54.7\% of the population studied earned over $2000 €$ net per month, and $23.6 \%$ earned over $3000 €$. Half of the respondents lived in urban or peri-urban areas, and the other half lived in rural areas, $61 \%$ lived nearby (in the gateway towns) or within the Massif of Bauges.

In the winter, $80 \%$ of the people surveyed practiced ski touring, and $20 \%$ practiced snowshoeing. The frequency and level of practice were both high: $75 \%$ of the people surveyed practiced their sport at least once a week, and $85 \%$ of them had an advanced or expert level. The main motivation for the practice was the contact with nature. The activity was mainly conducted with friends $(75 \%)$, followed by family $(21 \%)$. The other main sports activities practiced include climbing, hiking and mountain biking. It is therefore possible to observe a consistency in their athletic tastes, since in accordance with Pociello's sports space (1995), these are all sports that are predominantly technological and informational, with a tendency towards ecologization for the people equipped with more cultural capital.

Establishing an MCA makes it possible to distinguish between different categories of practitioners. Table 1 indicates the absolute contribution of each active category and their factorial coordinates.

Table 1. Absolute contribution of the factor and factorial coordinate of each active category of variables.

\begin{tabular}{|lr|r|r|r|}
\cline { 2 - 6 } \multicolumn{1}{c|}{} & \multicolumn{2}{|c|}{ F1 } & \multicolumn{2}{c|}{ F2 } \\
\hline Chategories & Contribution & Factorial coordinates & Contribution & Factorial coordinates \\
\hline Snowshoeing & 42 & -187 & 64 & 723 \\
\hline More than once a week & 34 & 193 & 125 & -838 \\
\hline Less than once a week & 93 & -1022 & 20 & -285 \\
\hline Very easy & 105 & 873 & 24 & 347 \\
\hline Easy & 38 & 792 & 91 & 782 \\
\hline Difficult & 17 & 115 & 64 & 499 \\
\hline Very difficult & 71 & -234 & 27 & 164 \\
\hline Beginners/intermediate & 24 & -741 & 87 & -713 \\
\hline Advanced & 73 & 602 & 22 & 148 \\
\hline Expert & 72 & -671 & 18 & 181 \\
\hline Competition & 132 & -998 & 32 & -507 \\
\hline Pleasure & 111 & -726 & 48 & -398 \\
\hline Physical commitment & 11 & 89 & 97 & 612 \\
\hline Physical maintenance & 95 & -1003 & 22 & -123 \\
\hline Conviviality & 23 & 439 & 88 & -517 \\
\hline Landscape contemplation & 35 & 342 & 102 & 132 \\
\hline & 24 & 218 & 69 & 202 \\
\hline
\end{tabular}

Note: The absolute contribution of each active category represents the part of the factor's inertia due to the category to which it refers. For each factor, the sum of all the absolute contributions of the active categories is equal to 
1000. The factorial coordinates establish the position of the categories on the axes, both in terms of distance from the origin-centre and in terms of the side (positive or negative) of factor considered.

Factorial axis 1 (21\% of the variance) opposes participants with high level and frequency of practice, competitors, and those motivated by surpassing themselves, with participants with an intermediary level and a lower frequency of practice. Factorial axis 2 (13,4\% of the variance) opposes snowshoers seeking contact with nature and physical fitness with participants using easy itineraries, with pleasure and conviviality as their main motivation. From those oppositions, participants were categorized into three groups. The curved lines in Figure 1 distinguish the different categories of participants.

The categories' names appear in quotation marks on the figure.

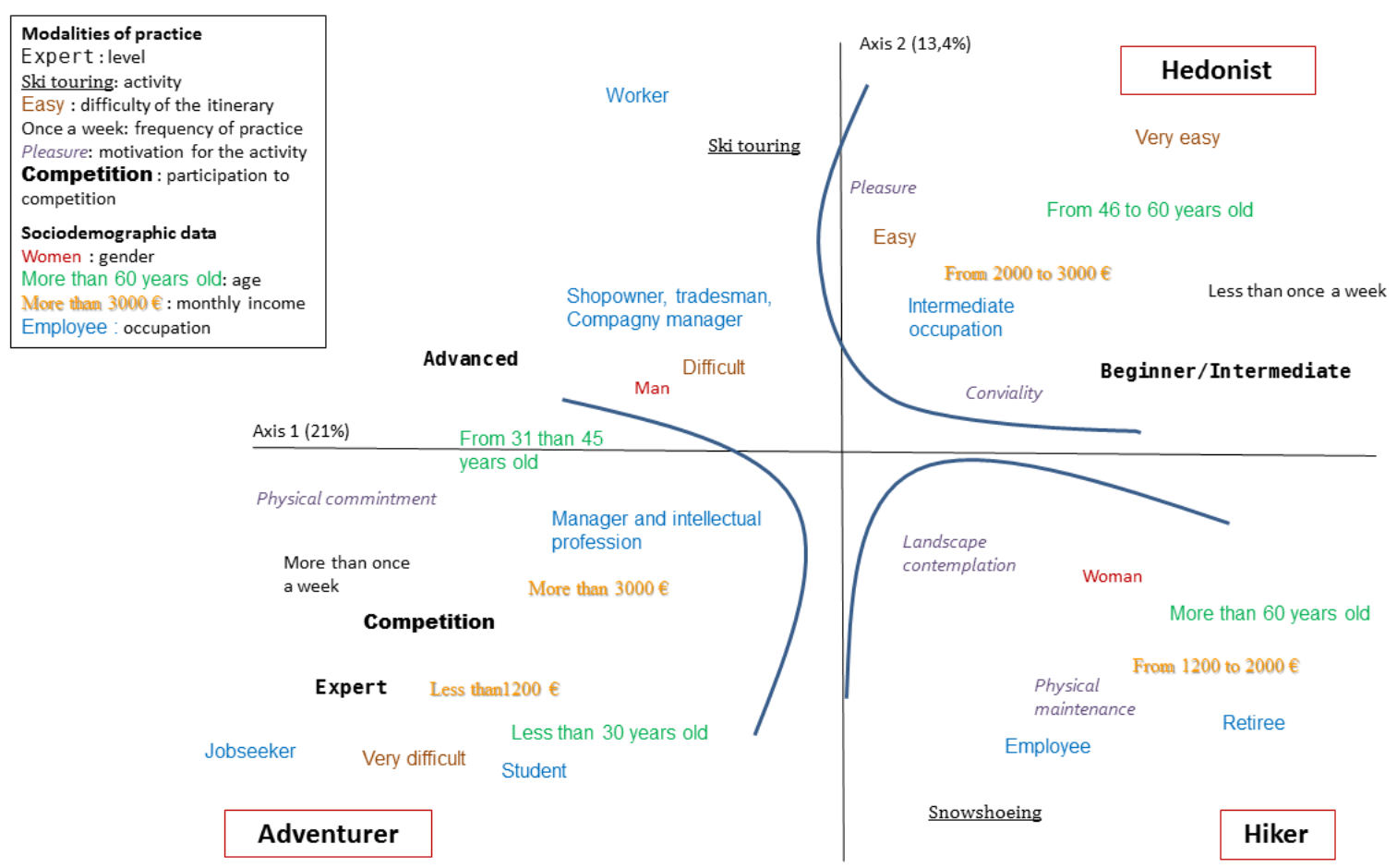

Figure 1. Profiles of the practitioners in the winter season.

The first category, the 'adventurers', includes the people who consider themselves experts. They practice more than once a week. This level and frequency of skiing grants them access to difficult and technical itineraries. This category includes the individuals who have climbed the Mont Pécloz (2197 m) and descended via the 'Grande Faille' route, classified with a difficulty score of 5.2 (on a scale to 5.6), involving intensive physical effort. This itinerary is sought for its technicality and its uniqueness: 'Déprofondis done right after the Grande Faille is amongst one the most beautiful itineraries of Europe because there are two couloirs one after another and they are very very enclosed. I've never experienced that anywhere else.' (R. L.). The practitioners in this category aim for intense commitment: 'Our practice is sort of out of the ordinary, since we like skiing down very steep slopes. So we're looking for new sensations and we want to ski in couloirs that have never been skied.' (Q. 312). 'I try to find the steepest possible slope (...) There's always this notion of intense effort that motivates me and accentuates the sensations and the pleasure.' (J. B.). The favourite motives are surpassing oneself and physical commitment, but performance and competition are also important. Indeed, all of the individuals practicing competitive ski mountaineering can be found in this profile: 'After three years of ski touring, I decided to start competitive skiing. (...) I do it mainly to try and place among the top racers or even to win.' (R. L.). Sociodemographic characteristics linked 
with this modality are men, the 'managers' occupational category and students. This category is connected to the age of the participants since people under 30 and 30 to 45 years old can be found in the group. Likewise, monthly incomes under 1200 or above $3000 €$ are represented in this category.

The second category, the 'hedonists', is composed of individuals who declare that they have an intermediate level and who practice roughly once a week. Most of them have been hiking for 25 years or more. They choose itineraries that are easy, or even very easy. This category contains people looking for pleasure and sensations but also social relations and conviviality, which explains the use of the term hedonist to refer to them. 'I'm looking more for the beauty of the outing than the athletic feat.' (B. R). They prefer the Bauges massif because of its proximity. In this group one also finds many members of the French Alpine Club (CAF) or the French Climbing and Mountain Federation (FFME), who joined either for the activities or simply for the group insurance policy. Intermediary occupations (such as technicians or clerical, services and sales workers) can be found in the group. Their monthly income belongs to the 2000-3000€ bracket and they are between 45-60 years old.

The third category, the 'hikers', contains almost exclusively snowshoers. They are motivated by staying in shape, as reflected by the other sports they practice; $60 \%$ of the sports practiced by the snowshoers are exercise sports (e.g. gymnastics, fitness, bodybuilding, aqua gym). 'A little bit of sports, some exercise, nature, being outside all day.' (Q. 128). The landscapes and the contact with nature are also important motivations, as seen in this interviewee comment: 'It's both to experience pleasure and to discover new things; things you've never seen before. Discovering new places, lakes. It's beautiful when you reach a lake. There's a feeling of fulfillment.' (C. P.) Tourists (i.e. people from outside of the Rhône-Alpes region who are vacationing in the massif) are over-represented in this group and have a fairly low frequency of practice (less than once a month). Sociodemographic characteristics linked with this group are women, retirees, and those over 60 years old. Income ranges between 1200 and $2000 €$ per month.

\section{The summer practitioners}

In the summer, a slight majority of the respondents were men $(55.8 \%) .72 \%$ of the population studied were over 40 years old, and $56 \%$ were over 50 . The under 30 age group represented only $19.4 \%$ of the total. Their educational level was also high, since $50.8 \%$ had a university degree or higher, and among them, $35.3 \%$ had an education level equivalent to or higher than a Master's, 34\% of the respondents were in managerial or higher intellectual occupations. Retirees represented a significant proportion of the sample, $22 \%$ of the respondents. Concerning their income, $52.4 \%$ of the interviewees earned over $2000 €$ net per month, and $23.8 \%$ earned over $3000 €$. The study of people's residences revealed that nearly $80 \%$ of the practitioners came from the Rhône-Alpes region, including 23\% from the municipalities inside of the Park and $18 \%$ from the gateway towns. Habitats were equally distributed between urban or peri-urban areas and villages or isolated locations.

The activity practiced was mainly hiking (95\% of the respondents). The remaining $5 \%$ were trail runners. The frequency of practice was not very high, since $35 \%$ of the people interviewed practiced the sport between one and three times a month, and $26 \%$ practiced only during holidays. Most practitioners had an advanced level (55\%), but there were very few experts (less than 10\%). Contact with nature was the predominant motivation for the practice. The activity was most often carried out as a family $(65 \%)$, or with friends $(45 \%)$.

Establishing an MCA makes it possible to distinguish between different categories of practitioners. Table 2 indicates the absolute contribution of each active category and their factorial coordinates. 
Table 2. Absolute contribution of the factor and factorial coordinate of each active category of variables.

\begin{tabular}{|c|c|c|c|c|}
\hline & \multirow{2}{*}{\multicolumn{2}{|c|}{$\mathrm{F} 1$}} & \multirow{2}{*}{\multicolumn{2}{|c|}{$\mathrm{F} 2$}} \\
\hline & & & & \\
\hline Categories & Contribution & Factorial coordinates & Contribution & Factorial coordinates \\
\hline Hiking & 56 & -206 & 13 & 27 \\
\hline Trail running & 24 & 625 & 122 & 813 \\
\hline More than once a week & 23 & 237 & 75 & 666 \\
\hline Less than once a week & 85 & -846 & 46 & 836 \\
\hline Very easy & 30 & -179 & 63 & 365 \\
\hline Easy & 67 & -353 & 18 & -178 \\
\hline Difficult & 37 & 724 & 62 & -425 \\
\hline Very difficult & 102 & 1114 & 12 & 417 \\
\hline Beginners & 28 & -517 & 55 & 423 \\
\hline Intermediate & 79 & -1096 & 29 & -638 \\
\hline Advanced & 42 & 378 & 58 & -507 \\
\hline Expert & 112 & 912 & 21 & 944 \\
\hline Competition & 52 & 709 & 104 & 861 \\
\hline Pleasure & 17 & 186 & 96 & -818 \\
\hline Physical commitment & 45 & 433 & 86 & 952 \\
\hline Physical maintenance & 88 & -1002 & 27 & -779 \\
\hline Conviviality & 75 & 598 & 34 & -1132 \\
\hline Landscape contemplation & 38 & -256 & 79 & -943 \\
\hline & $\begin{array}{l}\text { SUM = } \\
1000\end{array}$ & & $\begin{array}{l}\text { SUM = } \\
1000 \\
\end{array}$ & \\
\hline
\end{tabular}

Note: The absolute contribution of each active category represents the part of the factor's inertia due to the category to which it refers. For each factor, the sum of all the absolute contributions of the active categories is equal to 1000. The factorial coordinates establish the position of the categories on the axes, both in terms of distance from the origin-centre and in terms of the side (positive or negative) of factor considered.

As seen in Figure 2, factorial axis 1 (23,3\% of the variance) opposes participants with a high level and frequency of practice and following difficult to very difficult itineraries with participants of an intermediary level and a lower frequency of practice, using easier trails. This axis also opposes different types of motivations: conviviality and physical fitness. Factorial axis 2 (15,2\% of the variance) opposes trail runners and competitors or participants seeking to surpass themselves, with those motivated by pleasure or landscape contemplation. From those oppositions we defined four categories of participants. 


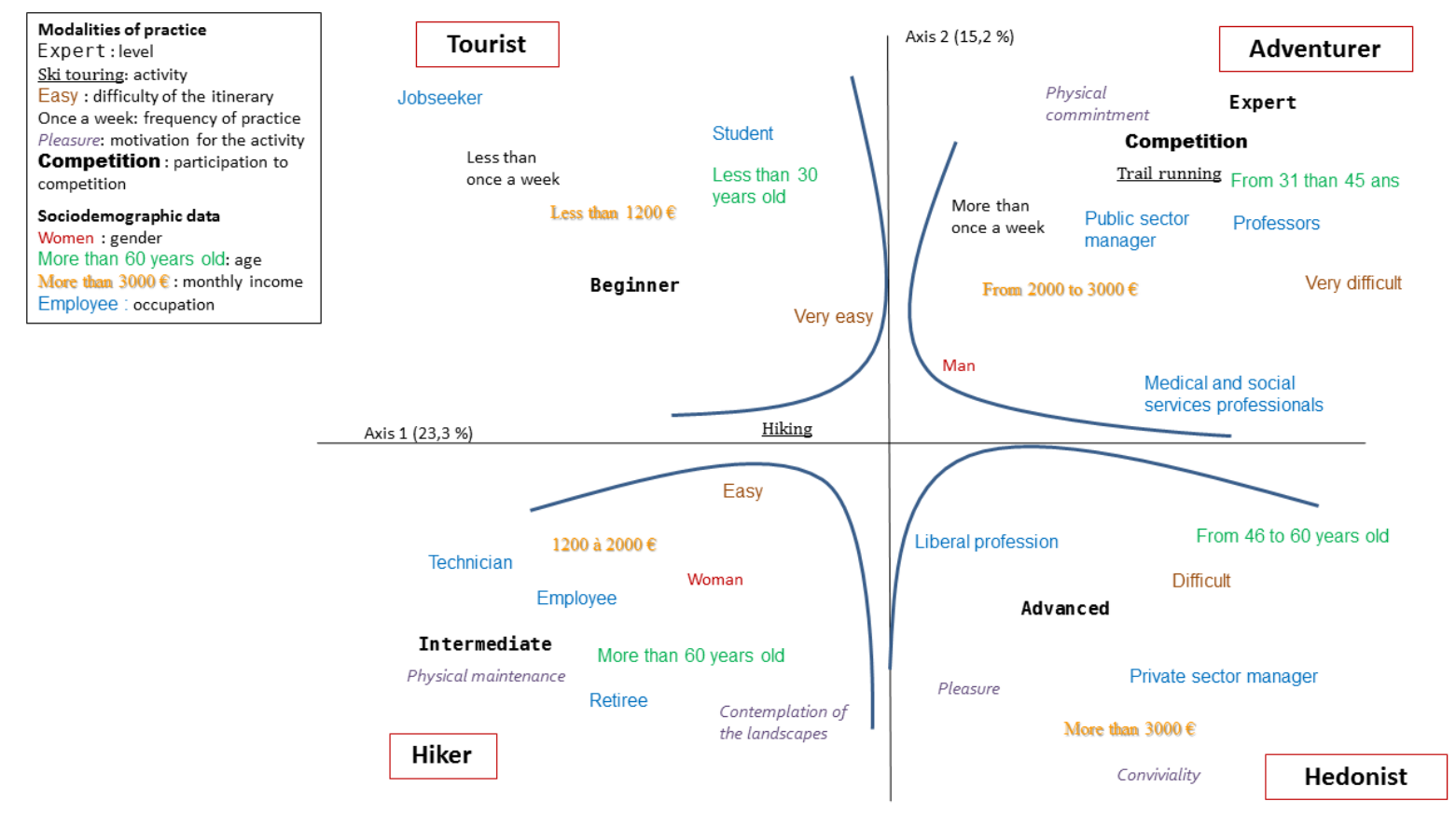

Figure 2. Profiles of the practitioners in the summer season.

The first category, the 'adventurers', includes the people who consider themselves experts. They follow itineraries rated 'very difficult' and hike more than once a week. They have an excellent experience level of the mountains, ranging from 20 to 30 years. This is the category that contains mountain specialists and competitive trail runners. It can be observed that they practice a wide variety of other sports, outdoor and indoor, but all very physical. The motivation to practice their sport is linked to the objective to surpass themselves: 'In the mountains I have to exert a physical effort. I can't imagine climbing a peak at $2 \mathrm{kmph}$ without sweating.' (A.C.). Therefore, they practice hiking at high altitudes, as well as mountaineering and they especially enjoy exploring new summits. Sociodemographic characteristics linked with this modality are men and professors and high school teachers, public sector managers, andmedical and social service professionals. Their net monthly income ranges from 2000 to $3000 €$. Participants between 31 and 45 years old are represented in this group.

The second category, the 'hedonists', is composed of individuals who declare that they have an advanced level in the activity and who hike roughly once a week. They choose itineraries that are rated from not very difficult to difficult. Most of them have been hiking for 30 years or more. Their 'hedonist' qualification is based on their motivations to hike in the massif, which are numerous but focused on pleasure, relaxation and breaking away from daily routine: 'I choose my hikes according to my desires (...) What I want is to be surrounded by nature, and take pleasure in it.' (M.H.). Conviviality is also an objective: 'When I cross paths with others, I like to chat.' (M.H.). Contrary to the 'adventurers' who hike alone, the 'hedonists' are accompanied by their spouses or members of an association. If they hike in a group, it is usually because they are members of a mountain sports federation. Professions linked with this modality are managers of the private sector and independent professionals. Their incomes are higher than those of the 'adventurers', with a net monthly income of over $3000 €$. The age range is between 46 and 60 years old.

The third category, the 'hikers', comprises mostly of people with an experience of the mountains dating back 10-20 years, and sometimes more. Hiking alone or in small groups, they declare that they have an intermediate level in the activity and choose itineraries that are rated as easy. Most often this choice of itinerary is motivated by an awareness of the risks: 'The most difficult thing can be the ridges, which I have never hiked on. I wouldn't dare go up there' 
(M.C.). Physical fitness also plays a role. Most of the members in this category live in municipalities within the Park, and hike from one to three times a month. Their outings mostly take place in the Massif of Bauges, even if they do not strictly limit themselves to it. These outings are either occasional or regular. The main reasons for the practice are physical exercise and contemplation of the landscape. Sociodemographic characteristics linked with this modality are women, technicians or employees ${ }^{4}$, as well as retirees, which helps to explain why participants over 60 are in this group. Their net monthly income ranges from 1200 to $2000 €$.

The people in the fourth category, the 'tourists', choose 'very easy' itineraries. With a beginner or intermediate level in the activity, they only hike during holidays. For some, it was their first outing in the mountains, while others had a limited experience of roughly 1-5 years, or 5-10 years. This category also includes the trail runners who are new to this type of sport and come from other French regions outside of Rhône-Alpes. Most of the time they come in families, and the presence of children often explains the choice of easy, short itineraries. Similarly, to all of the other profiles, the contemplation of the landscape is an important motivation. However, surpassing oneself is not a goal. The socio-demographic categories associated with this modality are fairly heterogeneous. They include primary school teachers, pupils and students, business managers, as well as jobseekers. Participants in this group are often less than 30 years old.

\section{Similarities and differences between the practitioners in the summer and winter seasons}

Whether in summer or winter, the recreational users of the Bauges are members of the privileged classes, with an over-representation of managers and higher intellectual occupations $^{5}$, accounting for $37.3 \%$ of the sample versus $14.3 \%$ of the French working population ${ }^{6}$. They are equipped with a rich educational baggage, since $57.7 \%$ of the respondents have a degree equal to or higher than the 3-year university level. University graduates are thus over-represented $^{7}$, since only $15.8 \%$ of the French population have a university degree. They also have a higher economic capital, since $24.5 \%$ earn over $3000 €$ net per month, versus $16 \%$ in the overall French population above 18 years old. High incomes are thus over-represented in the sample ${ }^{8}$. However, in the summer season the practitioners are older, with an average age of 52 , versus 43 in the winter. Likewise, the proportion of women is higher, $45 \%$ in the summer versus $25 \%$ in the winter. It is therefore possible to observe gender and age effects on the activities practiced.

Concerning the practice of the activity, the contact with nature is the reason the most often evoked in both summer and winter. The mountain environment is thus considered as a place to be preserved (for $88 \%$ of the respondents) and a restorative place for nearly half of the practitioners. The Massif of Bauges is particularly appreciated because it is considered to be a wild, preserved, authentic territory. It is perceived as less crowded than other massifs, creating its characteristic tranquillity: 'It seems miles away from civilization, although Chambéry and Annecy are at its feet. You're really not far at all, and yet you truly have the impression that you're in another world.' (R. L.). Between the summer and winter seasons, differences can be observed in terms of the number of years of experience in the activity, which is higher for the

\footnotetext{
${ }^{4}$ In the French classification of occupations 'employees' include low responsibility occupations such as clerical support workers or sales and services workers

${ }^{5}$ According to the Chi-Square adjustment test (ddl=6; $n=799 ;$ Chi-Square $\left.=831.55 ; \mathrm{p}<0.05\right)$

${ }^{6}$ Including jobseekers

${ }^{7}$ According to the Chi-Square adjustment test (ddl=4; $\mathrm{n}=1019$; Chi-Square=1496.23; $\left.\mathrm{p}<0.05\right)$

${ }^{8}$ According to the Chi-Square adjustment test $(\mathrm{ddl}=3 ; \mathrm{n}=957$; Chi-Square $=112.18 ; \mathrm{p}<0.05)$.
} 
summer hikers. This can be correlated with age, which is also higher for these practitioners. Yet the frequency and level of practice are lower.

Whether in summer or winter, the practitioners' profiles are similar. Therefore, the 'adventurers', 'hedonists' and 'hikers' can be distinguished by the way in which they practice the activity. While the first group aims for physical commitment and surpassing themselves, the second group is looking for pleasure, sensations and social relations, and the third group practices with the goal to stay in shape. The adventurers are mainly young city dwellers from privileged social categories. The hedonists include intermediary occupations and they are between 45 and 60 years old. The hikers are mainly women, older, and retired.

Whether in summer or winter, very few people in the sample compete in their activity. In the summer, this is logical, since there is no organized competition for hiking. The few competitors interviewed were trail running practitioners. In the winter, ski mountaineering competitors were more numerous, but they still represented only $5.7 \%$ of the sample. For this reason, they are integrated in the 'adventurers' category. However, the interviews made it possible to distinguish between these two types of practitioners. While the 'adventurers' interviewed were not opposed to competition, this type of practice does not correspond to their desire to immerse themselves in the wilderness, since the environment has been tamed for racing purposes: 'For me it's totally opposite to my own practice, because in racing, the route is totally laid out for them, and they just follow the tracks.' (X. P.) Nevertheless, they are receptive to the performance achieved: 'I admire these guys who compete, since they race at an impressive speed. But it's just not my personal vision of the mountains.' (J. B.).

One difference that can be observed between summer and winter is the absence of the 'tourists' during the winter season. This is due to the fact that the Hautes-Bauges are not considered a tourist destination in winter, since there are no ski resorts, aside from La Sambuy, which remains a small, middle mountain resort. Tourists from outside of the Rhône-Alpes region are thus rare and the practitioners are essentially people coming for a one-day excursion.

\section{Discussion}

\section{Socially selective practices}

From a general standpoint, whether in summer or winter, the profiles of the recreational users in the Massif of Bauges in general (all categories included) are compatible with the previous observations made of those visiting natural areas, and especially of those participating in adventure sports (Beedie and Hudson 2003b; Hardiman and Burgin 2010). They are mainly men over 40 years old, who are university graduates and belong to privileged social categories. Most of these practitioners, therefore, possess a high volume of capital, including a considerable share of educational capital, like cross-country skiing practitioners (Roult et al. 2017) or alpinism practitioners (Pomfret and Bramwell 2014). As shown by Pociello (1995, 203), the upper social classes, highly equipped with cultural capital, have a marked preference for 'predominantly technological and informational' practices, with a tendency towards ecologization.

However, it is possible to observe differences between ski touring activities and hiking activities (in summer and on snowshoes). Some of these differences are similar to those observed between hikers and mountain bikers (Heer, Rusterholz, and Baur 2003). Thus, as with mountain bikers, ski touring practitioners are mainly men (78\%). They are younger than the hikers and have a higher level of education. They are strongly committed to the activity, with a regular practice at least once a week for $65 \%$ of them, and a high level in the activity (78\% of them declare that they have an advanced or expert level). Ski touring practitioners are, therefore, closer to the profiles observed among 'lifestyle sports' practitioners (Wheaton 2004, 2010), with a 
predominance of men and higher social classes. Male domination can be explained by the fact that risk (Stoddart 2010; Penin 2012), linked in particular to the steepness of the slopes and the snow mantle, is inherent to the practice of ski touring. Results show that women tend to choose easier itineraries. They are underrepresented in the 'adventurers' category, a category which uses the most difficult, riskier itineraries. These results tally with surveys on outdoor sports practitioners' motivations which show thatmen aremotivated by risk taking and danger (Ewert et al. 2013; Sport England 2015). As with other mountain sports, this gender difference can be explained by the prevalence of social stereotypes, in particular the fact that courage is still considered to be a male trait that explains men's aptitude to take more risks than women (Penin 2007; Laurendeau and Sharara 2008). These stereotypes are particularly conveyed by the media (Thorpe 2005).

As for the predominance of wealthier classes, this can be explained by the amounts of time and money invested in the activity, but also by the type of relationship with the body. Indeed, the practice of instrumented sports is already socially segregational due to the amount of time consumed to learn them and to make progress. It also requires the application of 'reflex dispositions relying on swiftness and on the adjustment of the motor response that is necessary to the guidance of a mobile device in addition to an harmony in decisional choices at all times' (Pociello 2015, 21)

Therefore, these sports require cultural properties, in-depth knowledge and informational skills acquired outside of the actual sports domain. All of these are properties that correspond to those of the privileged social classes. Dispositions acquired during sports practice can then be transferred to the professional world. This can also explain the investment of wealthier classes in the informational sports, as is the case for adventure sports (Kay and Laberge 2002) and high-risk sports (Fletcher 2008).

\section{Differentiated modalities of practice}

The results of the survey allow us to differentiate various modalities of practice in the Bauges mountain range. The typologies can help managers to better communicate about the mountain range for marketing purposes (Salome and Van Bottenburg 2012).

As in other studies conducted on mountain sports practices, these results highlight individuals' different usages of the same activity and reveal systems of opposition between these different modalities of practice. Thus, it was possible to identify three profiles in the winter and summer seasons: the 'adventurers', the 'hedonists' and the 'hikers'. The first two correspond to the 'hedo-mountaineers' and the 'mountain adventurers' identified by Corneloup (2003), whereas the third corresponds to the 'women hikers' interviewed in the Massif du Mont-Blanc (Lefèvre 2004). For the 'hedo-mountaineers', 'the attraction of a beautiful walk outdoors to discover the beauties of the mountains thanks to a physical practice enabling this encounter with a welcoming environment appears to be the dominating factor within this form' (Corneloup 2003, 151). The 'mountain adventurers' are attracted by the idea of testing themselves and aim to immerse themselves in an untamed, more authentic wilderness. The 'hikers' practice different forms of hiking at medium altitudes, with the objective being to contemplate the landscapes.

In the summer season, the 'tourist' profile joins the three previous ones. Therefore, in the summer, as for canyoneering (Suchet and Jorand 2009), it is possible to observe a division between a consumerist logic within the industry of leisure and tourism followed by 'tourists' who practice the activity in the same way that they would take a tour or attend a show, and a logic of sustainable investment in the practice followed by the 'adventurers' and 'hedonists'. Contrary to the surveys conducted on canyoneering (Suchet and Jorand 2009) or canoeingkayaking (Lapierre 1981), it was not possible to distinguish here the 'passionate purists' who organize trips devoted to their activity in specially equipped cars or vans, or who even organize 
their life around the practice, whereby the latter becomes serious leisure (Stebbins 2007). In the framework of our survey, while some people organize trips to practice their activity, it does not become a serious leisure. Likewise, the 'competitors' do not represent a separate category, as is the case in canoeing-kayaking (Lapierre 1981) and in summer mountain practices (Corneloup 2003). Instead, they are integrated in the 'adventurers' category. Results show that competition does not correspond to respondents' desire to immerse themselves in the wilderness. Furthermore, like the 'tourists' in canoeing-kayaking, 'fairly reserved with respect to competition, they are nevertheless receptive to the feats of other white water enthusiasts' (Pociello 1995).

\section{Implications}

Finally, it is possible to identify an age and gender effect in the structuring of the modalities of practice. Concerning age, it is possible to observe an increase in the age of the practitioners when moving from the 'adventurers' category to that of the 'hedonists', and then to that of the 'hikers'. Although the categories of practitioners are not identical, these effects of age and generations can be observed in the practice of canoeing-kayaking when former competitors invent new types of practice based on adventurous feats (Lapierre 1981). These results also tally with Sport England's survey which shows that the 'challenger' category, whose main motivation is 'pushes self to best previous physical performance' (Sport England 2015, 37), attracts younger practitioners. On the other hand, older practitioners are usually in the 'explorer' category, whose main motivation is to explore scenery where they like spending time with friends and family. Relaxing and unwinding are more important factors than health and exercise for these participants (Sport England 2015).

Moreover, it is possible to observe a gender effect, illustrated by the different investment by men and women in the practice. In the winter, women enjoy snowshoeing on itineraries that are not very difficult. Men are associated with the category 'adventurers', who choose the most difficult itineraries with a greater exposure to risk. While women are present among the 'hedonists', this is because they accompany their spouses or male friends and no group composed only of women was identified. A similar finding was reported in the case of canyoneering (Suchet 2009). Thus, just like adventure climbing (Holland-Smith 2014) or highrisk sports (Penin 2012), association with men has facilitated their access to opportunities that enable them to develop as practitioners. In the summer, men are also associated to the category 'adventurers' (i.e. those who prefer hiking at high altitudes). These results are similar to those of the survey conducted with users of Mont-Blanc (Lefèvre 2003), since they reveal a distinction between the low mountains as a space chosen by the 'hikers' and the high mountains, the preferred territory of the 'high-level mountaineers'. This is also in line with the work of Stoddart (2010), which highlights the gender-based marking of alpine skiing spaces. Indeed, the undeveloped mountain areas ideal for backcountry skiing are perceived as masculine spaces, while the developed areas in the ski resorts where the risks are lower are perceived as neutral or even feminine spaces (Stoddart 2010). There are, therefore, gender-based differences in the territorialisation of the mountains.

\section{Conclusion}

The survey carried out for the purposes of this study shows that the winter and summer hiking practices in the Massif of Hautes-Bauges are socially selective. Indeed, since the 1980s and the first surveys conducted with sports practitioners in France, social expansion remains relatively low for these outdoor sports activities, even more so when they require technical equipment, as is the case for ski touring. Beyond this global approach, it is possible to highlight different 
usages of the same recreation activity area, revealing systems of opposition that endure between the types of practice. It is here that gender appears to be a particularly structuring variable in the different recreational uses of the mountain environment. These results, therefore, fill a knowledge gap, in particular concerning winter practitioners, since no study has yet specifically focused on ski touring practitioners. The choice of the Massif of Bauges proved to be particularly relevant, since its marked relief allows several forms of hiking.

For managers, in-depth knowledge of visitors is important because it allows them to improve the actions implemented within the territories. Regarding, for example, satisfaction of visitors in the 'hikers' category, work on signs and marking of some easy itineraries could meet their need for safety. Furthermore, the presence of different categories of practitioners who are not seeking the same benefits for their practice could increase the occurrence of conflicts. Knowing peoples' motivations for visiting the area can help to find trails that facilitate conflict resolution. Finally, regarding the impact of outdoor recreation on wildlife, knowing the visitors will allow managers to target each category better with awareness campaigns. For example, the 'adventurers', who are always looking for new isolated itineraries, might cross formerly unexplored areas that can be considered refuge areas for wildlife. It thus seems necessary to raise awareness about the need for pristine areas to remain as such in order to preserve the wellbeing and tranquillity of wildlife.

One of the limits of this study is that most of the itineraries, especially those for ski touring, are difficult, thus limiting the presence of beginners. Therefore, it appears necessary to expand the data collection to include other territories, in order to obtain a more global vision of the types of hiking practices in the Alps and beyond. Furthermore, it appears necessary to complement the more quantitative approach of this study with indepth interviews in the form of 'sociological portraits' (Lahire 2006) in order to better understand the social processes at play in the engagement and investment in these activities. In particular, this requires mobilizing a qualitative methodology based on life stories, allowing a better understanding of the cultural dissonances at play. Finally, a more detailed analysis of the gender-based social relationships in these activities where male domination continues would be particularly relevant. Through life stories, but also the ethnographic observation of the locations of practice, the aim would be to try to understand the way in which women practitioners engage in the most intensive modalities of practice, and to analyse the gender-based social relationships during the activity.

\section{Acknowledgements}

The authors thank Elsa Girardeau who participated in the summer data collection and analysis for her master thesis

\section{Disclosure statement}

No potential conflict of interest was reported by the authors.

\section{Funding}

This work was supported by Agence Nationale de la Recherche; LABEX ITEM.

\section{Notes on contributor}

Clémence Perrin-Malterre, is a lecturer at EDYTEM of Savoie Mont Blanc University since 2012. Her research, in the field of sport sociology, focus on outdoor sports and sport tourism. She studies (1) the environmental management of outdoor sports in protected areas; (2) the tourist diversification of low mountain; (3) the evolution of sport tourism offer. Since 2013, she develops interdisciplinary project with ecologists and geographers to study how outdoor recreation affect the mountain ecosystem, and more specifically the interrelationship between 
recreationists and mountain wildlife. In order to understand this, researchers develop an integrated analysis of (1) the use and perceptions of the environment by outdoor activities participants, (2) the shared spaces between humans and wildlife and (3) the management guidelines. Furthermore, the goal of theses research is to provide data and knowledge required by protected areas managers who are facing an increasing number of outdoor activities on their territory.

Laine Chanteloup is a tenure track professor in geography of mountain resources at the Institute of Geography and Sustainability in Lausanne University. Laine Chanteloup's research interests focus on howhumans relate to their environment inmountain areas and in arctic regions. She is currently involved in a research project looking at the interactions between outdoor activities and wildlife in the Alps.

Léna Gruas is a Ph.D. student in sociology at the university of Savoie Mont Blanc. Her research interests include the environmental impact of sports and her current work investigates the human dimension of wildlife disturbance caused by mountain sports.

\section{References}

Ankre, R., P. Fredman, and A. Lindhgen. 2016. "Managers' Experiences of Visitor Monitoring in Swedish Outdoor Recreational Areas." Journal of Outdoor Recreation and Tourism 14: 35-40.

Arnould, E. J., and L. Price. 1993. "River Magic: Extraordinary Experience and the Extended Service Encounter." Journal of Consumer Research 20: 24-45.

Audinet, L., C. Guibert, and A. Sébileau. 2017. Les «sports de nature ». Vulaines-sur-Seine: Editions du Croquant.

Augustin, J. P. 2011. "Qu'est-ce que le sport ? Cultures sportives et géographie.” Annales de géographie 680: 361-382.

Beedie, P., and S. Hudson. 2003a. "Emergence of Mountain-based Adventure Tourism." Annals of Tourism Research 30 (3): 625-643.

Beedie, P., and S. Hudson. 2003b. Sport and Adventure Tourism. New York: The Haworth Press.

Berbeka, J. 2018. "The Value of Remote Arctic Destinations for Backcountry Skiers." Scandinavian Journal of Hospitality and Tourism 18 (4): 393-418.

Bessy, O. 2008. "La mise en loisir du sport. L'ambiguité des pratiques." In Loisirs, sports et sociétés. Regards croisés, edited by G. Ferreol and G. Vieille-Marchiset, 43-54. Besançon: Presses universitaires de Franche-Comté.

Blanchet, A., and A. Gotman. 2005. L'enquête et ses méthodes: l'entretien. Paris: Armand Colin.

Borgers, J., E. Thibaut, H. Vandermeerschen, B. Vanreusel, S. Vos, and J. Scheerder. 2015. "Sport Participation Styles Revisited: A Time-trend Study in Belgium from the 1970s to the 2000s." International Review for the Sociology of Sport 50 (1): 45-63.

Bourdieu, P. 1979. La distinction. Critique sociale du jugement. Paris: Ed. de minuit.

Breivik, G. 2010. "Trends in Adventure Sports in a Post-modern Society." Sport in Society 13: 260-273. Corneloup, J. 2003. "Les cultures sportives de la montagne d'aujourd'hui et de demain." In Les Pyrénées entre deux mondes, edited by F. Bartczak and J. Rage, 133-158. Perpignan: Presses universitaires de Perpignan.

Di Franco, G. 2016. “Multiple Correspondence Analysis: One Only or Several Techniques?” Quality \& Quantity - International Journal of Methodology 50 (3): 1299-1315.

Ewert, A., K. Gilberston, Y. C. Luo, and A. Voight. 2013. "Beyong 'Because It's There': Motivations for Pursuing Adventure Recreational Activities." Journal of Leisure Research 45 (1): 91-111.

Fletcher, R. 2008. "Living on the Edge: The Appeal of Risk Sports for the Professional Middle Class." Sociology of Sport Journal 25: 310-330.

Ganassali, S. 2007. Les enquêtes par questionnaire avec Sphinx. Paris: Broché.

Ghiglione, B., and R. Matalon. 1991. Les enquêtes sociologiques. Théories et pratique. Paris: Armand Colin.

Green, K., M. Thurston, and O. Vaage. 2015. "Isn't it Good, Norwegian Wood? Lifestyle and Adventure Sports Participation among Norwegian Youth.” Leisure Studies 34 (5): 529-546. 
Gundersen, V., M. Mehmetoglu, O. I. Vistad, and O. Andersen. 2015. "Linking Visitor Motivation with Attitude Towards Management Restrictions on Use in a National Park." Journal of Outdoor Recreation and Tourism 9: 77-86.

Hardiman, N., and S. Burgin. 2010. "Visit Impacts and Canyon Management in the Blue Mountains, Australia: Canyoners' Perspectives and Wilderness Management." Managing Leisure 15 (4): 264-278. Hardiman, N., and S. Burgin. 2011. "Canyoning Adventure Recreation in the Blue Mountains World Heritage Area (Australia): The Canyoners and Canyoning Trends Over the Last Decade." Tourism Management 32 (6): 1324-1331.

Heer, C., H. P. Rusterholz, and B. Baur. 2003. "Forest Perception and Knowledge of Hikers and Mountain Bikers in Two Different Areas in Northwestern Switzerland." Environmental Management 31 (6): 709-723.

Holland-Smith, D. 2014. “'All the Places We Were Not Supposed to Go': A Case Study of Formative Class and Gender Habitus in Adventure Climbing." Sport, Education and Society 21 (8): 1176-1192.

Humberstone, B., H. Prince, and K. A. Henderson. 2015. Routledge International Handbook of Outdoor Studies. London: Routledge.

Immoos, U., and M. Hunziker. 2015. "The Effect of Communicative and On-site Measures on the Behaviour of Winter Sports Participants Within Protected Mountain Areas - Results of a Field Experiment." Eco.mont-Journal on Protected Mountain Areas Research and Management 7 (1): 17-25. Jorand, D. 2000. "Histoire et sociologie du vol libre français. Structure, oppositions, enjeux." PhD en STAPS, Université de Paris Sud Orsay.

Kay, S., and S. Laberge. 2002. "The 'New' Corporate Habitus in Adventure Racing." International Review for the Sociology of Sport 37 (1): 17-36.

Kerr, J. H., and S. Houge Mackenzie. 2012. "Multiple Motives for Participating in Adventure Sports." Psychology of Sport and Exercise 13: 649-657.

Kim, H., and H. Song. 2017. "Measuring Hiking Specialization and Identification of Latent Profiles of Hikers." Landscape and Ecological Engineering 13 (1): 59-68.

Ko, Y. J., H. Park, and C. L. Claussen. 2008. "Action Sports Participation: Consumer Motivation." International Journal of Sports Marketing \& Sponsorship 9: 111-124.

Lahire, B. 2004. "Sociologie dispositionnaliste et sport. Généralistes et Spécialistes." In Dispositions et pratiques sportives, edited by J. Defrance and J. P. Clément, 23-33. Paris: L'Harmattan.

Lahire, B. 2006. La culture des individus. Dissonances culturelles et distinction de soi. Paris: La découverte.

Lahire, B. 2007. L'esprit sociologique. Paris: La Découverte.

Lahire, B. 2013. Dans les plis singuliers du social. Individus, Institutions, Socialisations. Paris: La

Découverte.

Lapierre, A. 1981. Sports de pleine nature et pratiques sociales. Analyse socioculturelle du canoë-kayak et de l'escalade. Paris: Mémoire pour le diplôme de l'INSEP.

Laurendeau, J., and N. Sharara. 2008. "Women Could Be Every Bit as Good as Guys: Reproductive and Resistant Agency in Two 'Action' Sports.” Journal of Sport \& Social Issues 32 (1): 24-47.

Lee, KoFan, R. Mowatt, K. Goff, C. Novotny, A. Rivin, and A. Walter. 2016. "The Perceptions and Reflections on Racial/Ethnicity Diversity in Outdoor Recreation.” Journal of Cultural Diversity 23 (4): $158-164$.

Lefèvre, B. 2004. "Contribution to the Study of the Social Structure of High-altitude Mountain Activities: Example of Users in the Mont-blanc Massif." Journal of Alpine Research 92 (4): 76-85.

Lefèvre, B., and F. Ohl. 2012. "Consuming Sports: Distinction, Univorism and Omnivorism." Sport in Society 15: 44-63.

Manning, R. E. 2010. Studies in Outdoor Recreation: Search and Research for Satisfaction. Corvallis: Oregon State University Press.

Nétumières, F. 1997. "Méthodes de regression et analyse factorielle." Histoire \&Mesure 12 (3/4): 271297.

O'Connell, T. S. 2010. "The Effets of Age, Gender and Level Experience on Motivation to Sea Kayak." Journal of Adventure Education and Outdoor Learning 10 (1): 51-66.

Ohl, F., and M. Taks. 2008. "La consommation sportive. Etat des lieux." Revue française de marketing 219: 27-46. 
Paillé, P., and A. Mucchielli. 2003. L'analyse qualitative en sciences humaines et sociales. Paris: Armand Colin.

Penin, N. 2007. ““'Sports à risque”: production, permanences et résistances à la domination masculine.” Nouvelles questions féministes 26: 90-105.

Penin, N. 2012. Les sports à risque. Sociologie du risque, de l'engagement et du genre. Arras: Artois Presses Université.

Pigram, J., and J. M. Jenkins. 2006. Outdoor Recreation Management. New-York: Routledge.

Pociello, C. 1981. Sports et société. Approche socioculturelle des pratiques. Paris: Vigot.

Pociello, C. 1995. Les cultures sportives. Paris: Presses Universitaires de France.

Pociello, C. 2015. " « Nouvelles pratiques, nouvelles valeurs » : essai sur la transformation de quelques « milieux de culture » sportifs après les années 1980.” STAPS 107: 13-31.

Pomfret, G., and B. Bramwell. 2014. "The Charactéristics and Motivational Decisions of Outdoor Adventure Tourists: A Review and Analysis." Current Issues in Tourism 19 (14): 1447-1478.

Robinson, V. 2004. "Taking Risks: Identity, Masculinities and Rock Climbing." In Understanding Lifestyle Sports. Consumption, Identity and Difference, edited by B. Wheaton, 113-130. London: Routledge.

Roult, R., N. Domergue, D. Auger, and J.-M. Adjizian. 2017. "Cross-country Skiing by Quebecers and Where They Practice: Towards 'Dwelling' Outdoor Recreational Tourism.” Leisure/Loisir 41 (1): 6989.

Salome, L., and M. Van Bottenburg. 2012. "Are They all Daredevils? Introducing a Participation Typology for the Consumption of Lifestyle Sports in Different Settings." European Sport Management Quarterly 12 (1): 19-42.

Sport England. 2015. Getting Active Outdoors: A Study of Demography, Motivation, Participation and Provision in Outdoor Sport and Recreation in England.

Stebbins, R. A. 2007. Serious Leisure: A Perspective for Our Time. New Brunswick, NJ: Transaction.

Stoddart, M. 2010. "Constructing Masculinized Sportscapes: Skiing, Gender and Nature in British Columbia, Canada." International Review for the Sociology of Sport 46 (1): 108-124.

Suchet, A. 2009. "Relations de genre et masculinités dans les pratiques de canyoning." In Femmes et hommes dans les sports de montagne, edited by C. Ottogalli-Mazzacavallo and J. Saint-Martin, 391408. Grenoble: Maison des Sciences de l'Homme des Alpes.

Suchet, A., and D. Jorand. 2009. "La fréquentation des sites naturels de canyoning: une approche socioculturelle." Karstologia 26 (53): 15-26.

Thiéry, P. 2013. "Les sports de nature en France en 2011." Stat-info 13-04.

Thorpe, H. 2005. "Jibbing the Gender Order: Females in the Snowboarding Culture." Sport in Society 8: 76-100.

Torbidoni, E. I. F. 2011. "Managing for Recreational Experience Opportunities: The Case of Hikers in Protected Areas in Catalonia, Spain." Environmental Management 47 (3): 482-496.

Wheaton, B. 2004. "Introduction: Mapping the Lifestyle Sport-scape." In Understanding Lifestyle Sports. Consumption, Identity and Difference, edited by B. Wheaton, 7-8. London: Routledge.

Wheaton, B. 2010. "Introducing the Consumption and Representation of Lifestyle Sports." Sport in Society 13: 1057-1081.

Wheaton, B. 2014. The Consumption and Representation of Lifestyle Sports. London: Routledge 